\title{
ASSOCIAÇÕES ENTRE CMMI-DEV 1.2 E ISO/TS 16949
}

\section{ASSOCIATION BETWEEN CMMI-DEV 1.2 AND ISO/TS 16949}

\author{
Altamar Urbanetz de Araújo Albanez* E-mail: altamar@outlook.com \\ Carla Cristina Amodio Estorilio* E-mail: amodio@utfpr.edu.br \\ * Universidade Tecnológica do Paraná (UTFPR), Curitiba, PR.
}

\begin{abstract}
Resumo: O setor automotivo é um dos mais arrojados em termos de qualidade, demandando a certificação ISO/TS 16949. Apesar disso, algumas empresas a perdem ou obtêm poucas melhorias por indícios de que não possuam maturidade suficiente para manter essa certificação, nem diretrizes para melhoria contínua. Considerando que o CMMI é um dos métodos de diagnóstico de maturidade, o objetivo desse trabalho é identificar a viabilidade de associar a ISO/TS $16949 \mathrm{com}$ o CMMI-DEV 1.2. O procedimento metodológico adotado consiste em uma revisão sobre PDPs, certificação da qualidade e maturidade de processo e, posteriormente, uma associação entre os dois modelos. Da análise, conclui-se que uma empresa certificada pela ISO/TS não necessariamente atinge nem ao nível 2 de maturidade. Além disso, constata-se que, enquanto o CMMI aponta quais itens estão descobertos e devem ser desenvolvidos a ISO/TS apenas estimula a "melhoria contínua", sem um plano ou diagnóstico para a empresa atingi-la operacionalmente.
\end{abstract}

Palavras-chave: Processo de Desenvolvimento de Produtos. Certificação da Qualidade. ISO/TS16949. Maturidade de Processo. CMMI.

\begin{abstract}
The automotive sector is one of the most daring in terms of quality, requiring ISO/TS 16949 certification. Nevertheless, there are companies those lose their certification or develop only some improvements due to a lack of enough maturity to maintain it and gaps in continuous improvement guidelines. Whereas CMMI is one of the diagnostic methods of maturity, the aim of this work is to identify the feasibility of linking the ISO/TS 16949 with the CMMI-DEV 1.2. The method used consists in review PDPs, quality certification and process maturity and then associate these two models. The analysis concludes that a company certified by ISO/TS not necessarily even reaches the maturity level 2 in CMMI. Moreover, while the CMMI model shows those items not covered and demand their development, ISO/TS only encourages "continuous improvement" without a plan or diagnostics for the company operationally achieve it.
\end{abstract}

Keywords: Products Development Process. Quality Certification. ISO/TS 16-949. Process Maturity. CMMI.

\section{INTRODUÇÃO}

Com a globalização, torna-se evidente a necessidade das empresas planejarem o desenvolvimento dos seus produtos buscando soluções inteligentes e geração de valor. Os elevados números de lançamentos e desativações de produtos

Revista Produção Online, Florianópolis, SC, v.14, n. 2, p. 679-702, abr./jun. 2014. 
fazem com que as indústrias, principalmente as do setor automotivo, tenham que manter o alto padrão de qualidade para atingir a satisfação dos clientes. Visando atestar essa qualidade frente ao mercado nacional e internacional, as empresas buscam a certificação. Nesse sentido, a certificação da qualidade ISO é a mais aceita no que se refere à regulamentação internacional de comércio (RUZEVICIUS, 2008). A norma ISO 9001:2008 apresenta os requisitos para os Sistemas de Gestão da Qualidade (SGQ), que permanece estabelecido como o padrão mundialmente aceito para a prestação de garantias sobre a capacidade de satisfazer os requisitos de qualidade e aumentar a satisfação dos clientes em relação ao fornecedor-cliente. No caso do setor automotivo, é obrigatório atestar essa qualidade por meio da obtenção da certificação ISO/TS 16949 (ABNT/CB-25, 2010). Esta é controlada de forma centralizada pela International Automotive Task Force (IATF), a qual credencia mundialmente os Organismos de Certificação.

A ISO/TS 16949 é um sistema de gestão da qualidade que proporciona a melhoria contínua, enfatizando a prevenção do defeito e a redução da variação e desperdício na cadeia de fornecimento, alinhando e substituindo as normas até então adotadas nas organizações de produção automotiva pelo mundo. Também indica quais são os requisitos específicos da norma ISO-9001:2000 para as organizações de produção automotiva e de peças de reposição, além de incluir os catálogos e requisitos de cada cliente que participa da cadeia automotiva.

Segundo Rodrigues (2008), a ISO é considerada como um padrão mínimo para um SGQ. Além disso, esse certificado é válido por somente três anos, devendo ser renovado após esse período, cujo procedimento é chamado de "Auditoria de Recertificação", atestando a estabilidade do processo. Conforme as regras internacionais do IAF e do IATF, quando se refere à certificação ISO/TS 16949, a recertificação é obrigatória (FUNDAÇÃO CARLOS ALBERTO VANZOLINI, 2011).

Todavia, constatam-se indícios de que as empresas que perdem a certificação não possuem maturidade suficiente nem as diretrizes fornecidas pela ISO para planejar e executar as melhorias necessárias para a sua manutenção e ascensão. Entende-se por um Processo de Desenvolvimento de Produto (PDP) com alto nível de maturidade aquele considerado definido, gerenciável, passível de medição e controle, além de devidamente integrado, fundamental para o bom 
desempenho deste (QUINTELLA e ROCHA, 2007). Os autores Franzosi (2010), Lisboa (2010) e Vaz (2010) mediram o nível de maturidade de PDPs em três setores industriais, com um modelo simplificado do $\mathrm{CMMI}$, método utilizado para diagnosticar maturidade de processos de desenvolvimento, e constataram que as empresas que obtiveram a certificação almejada possuíam, no mínimo, nível 2 de maturidade, numa escala de 1 (mínimo) a 5 (máximo). Porém, as que estavam próximas do nível 2,0 tendiam a perder a certificação em curto prazo e as que estavam próximas a 2,9 ou mais mantinham essa certificação, obtendo, inclusive, melhorias com o decorrer do tempo. Alguns autores tentaram associar a ISO $9001 \mathrm{com}$ o modelo para medição e diagnóstico da maturidade, o CMMI-DEV 1.2, o qual também considera a integração do processo. Entretanto, os itens similares e complementares não foram explorados em detalhes para viabilizar a sua utilização conjunta. Quanto à norma ISO/TS 16949, não foi localizada qualquer associação desta com o CMMI-DEV 1.2.

Os autores Kitson et al. (2009) realizaram um trabalho que compara e contrasta o sistema da ISO 9000 com o CMMI-DEV 1.2, remetendo a correlação entre os dois modelos através de um quadro comparativo que identifica as áreas de processo do CMMI-DEV 1.2 e suas relevâncias com as descrições de processo da ISO 9000, porém, em um nível amplo e genérico. Pino et al. (2010) mostram um mapeamento da relação entre a ISO 12207:2008 e o CMMI-DEV 1.2, identificando que as áreas de processos deste são fortemente correlacionáveis às descrições de processo daquela, porém, também não abordam variáveis operacionais específicas dos dois sistemas.

Esses estudos apontam que a associação de modelos de maturidade com processos de certificação podem contribuir muito mais para o aumento de desempenho e maturidade das empresas do que a obtenção de uma certificação isolada. Entre os modelos existentes, muitos autores indicam o CMMI-DEV 1.2 para diagnosticar a maturidade de uma empresa e apontar os caminhos para que esta obtenha melhorias. Em especial, quando se aborda a união do CMMI-DEV $1.2 \mathrm{com}$ a ISO/TS 16949, pouco se encontra sobre o tema. Sendo assim, esse trabalho pretende mostrar os pontos em comum entre o CMMI-DEV 1.2 e a ISO/TS 16949, visando a ressaltar os pontos descobertos pela ISO que também devem ser 
melhorados para que a empresa realmente adquira qualidade e produtividade de longo prazo.

\section{MATURIDADE DE PROCESSOS E CERTIFICAÇÃO DA QUALIDADE}

\subsection{Conceitos e Modelos de PDP}

O PDP tem crescido em importância e diferencial competitivo dentro das empresas, sendo cada vez mais relevante para o sucesso das organizações no mundo contemporâneo. As organizações que desenvolvem produtos de sucesso de forma consistente, ou seja, produtos com integridade, normalmente são coerentes e integradas e se diferenciam não somente por sua estrutura estratégica, mas também pelo trabalho conduzido no dia a dia e pelo grau do entendimento individual (CLARK e FUJIMOTO, 1990).

Os autores que conceituam PDP o consideram segundo várias abordagens, desde as mais restritas à criação de um produto, internamente à empresa, até aqueles que levam em consideração todo o ciclo de vida do produto até o seu descarte.

Deschamps e Nayak (1997) definem PDP não apenas à luz de um produto, mas num sentido mais amplo, incorporando um processo completo com atividades que realize o desejo ou supra a necessidade dos clientes, bem como proporcione atendimento de suporte. Já para Rozenfeld et al. (2006), o PDP consiste em um conjunto de atividades que, além de permitir a criação de um produto considerando as necessidades do mercado e as possibilidades e restrições tecnológicas, também visa a atingir as estratégias competitivas e de produto da empresa.

O conceito de PDP defendido por Hartley (1998) mostra que a integração das tarefas e sistemas como um dos principais fatores para se desenvolver produtos bem sucedidos, seguida pela qualidade e flexibilidade dos sistemas de produção da empresa, enquanto que Paashuis e Boer (1997) enfatizam que o termo "integração" se refere ao envolvimento e à colaboração coletiva, destacando o fluxo de informação/comunicação recíproca, com informações disponíveis o mais cedo possível para evitar retrabalhos e perda de tempo.

Revista Produção Online, Florianópolis, SC, v.14, n. 2, p. 679-702, abr./jun. 2014. 
O modelo de PDP de Clark e Wheelwright (1993) possui um aspecto sequencial com enfoque na engenharia do produto e da produção, mas também com ações relacionadas ao marketing. Para Baxter (1998), a modelagem é representada por seis etapas de tomadas de decisões que representam uma sequência útil ao PDP, com vistas à redução dos riscos e incertezas.

Já o modelo de referência em PDP proposto por Rozenfeld et al. (2006), após anos de pesquisa na área, é mais abrangente do que os modelos tradicionais, dividido em três macrofases: pré-desenvolvimento, desenvolvimento e pósdesenvolvimento. Destaca-se que, com base neste modelo, este trabalho focaliza nas atividades da fase de desenvolvimento, sendo esta fase prioritariamente referente aos processos internos nas organizações.

O PDP específico da indústria automotiva foi, criado em 1995, um modelo que servisse para planejar e executar o desenvolvimento de produto, cujas etapas foram denominadas de Planejamento Avançado de Qualidade de Produto (APQP), visando minimizar a falhas de qualidade e comprometimento de prazos na indústria automotiva, consistindo em um método estruturado de trabalho que defina as etapas necessárias do PDP e com o objetivo de facilitar a comunicação entre todas as pessoas envolvidas no programa, assegurando que todas as etapas requeridas sejam realizadas dentro do prazo, em níveis aceitáveis de custo e de qualidade. Segundo Mello (2008), os principais objetivos das cinco fases do APQP consistem em: (i) Planejar e Definir Programa, (ii) Projetar e Desenvolver Produto, (iii) Projetar e Desenvolver Processo, (iv) Validar Produto e Processo, e (v) Avaliar, Retroalimentar e Tomar Ação Corretiva. Independentemente da etapa de desenvolvimento de produto, o fator qualidade deve imperar em cada atividade que compõe cada fase, incluindo no processo os desejos do consumidor.

\subsection{Qualidade e Certificações}

Segundo Slack et al. (2002), dentre as diferentes maneiras de definir as abordagens de qualidade, tem-se a abordagem transcendente, que vê a qualidade como "excelência inata"; a abordagem de manufatura, que a identifica como "livre de erros"; a abordagem com base no usuário, que coloca a qualidade como "adequada 
ao seu propósito"; a abordagem do produto, que a define como "um conjunto mensurável de características" e a abordagem baseada no valor, que conceitua a qualidade como um "equilíbrio entre o custo e a qualidade". Oakland (2007) cita que autores renomados definem a qualidade sob o ponto de vista da organização, como o atendimento às exigências do cliente. Slack et al. (2002) comentam que, para o consumidor, a qualidade é o resultado alcançado ao comparar as expectativas sobre o produto ou serviço com as suas percepções de desempenho.

As normas ISO reconhecem o sucesso e certificam a qualidade das práticas do sistema de gestão das organizações sendo a ISO essencial para negociar produtos e serviços em nível mundial. O Comitê Técnico Brasileiro (CB) desenvolveu 25 normas, as quais são revisadas a cada cinco anos.

Para buscar a certificação, as empresas devem criar processos mais estáveis, ressaltando-se a necessidade de entrega de produtos de melhor qualidade (PEKOVIC e GALIA, 2009), podendo exigir que seus fornecedores e prestadores de serviços também implantem determinada norma ISO, visando a garantir o sistema de qualidade até a entrega do produto ao cliente. Ao certificar o sistema de gestão, a organização prova que o mesmo foi avaliado por uma entidade independente, reconhecida por um organismo nacional de acreditação. Após três anos, o certificado precisa ser renovado, além disso, é necessário realizar auditoria semestral ou anual para verificar se segue atendendo aos requisitos da norma (RISSATO, 2009).

A norma ISO define princípios de gestão da qualidade como uma regra fundamental e abrangente para conduzir e operar uma organização, com o objetivo de melhorar continuamente o seu desempenho em longo prazo, pela focalização nos clientes e, ao mesmo tempo, encaminhar as necessidades de todas as partes interessadas (MELLO et al., 2009). Para Almeida et al. (2009), as empresas adotam a ISO como forma de obter as melhores práticas, visando a ajudá-las na estratégia e na manutenção de sua competitividade.

No setor automotivo, devido ao alto grau de exigência das peças integrantes de um automóvel, a norma ISO 9000 tornou-se muito genérica e, então, foram criadas normas específicas para o setor, como: "QS - Quality System Requirements 9000" (americana), “VDA - Verband der Automobil Industrie 6” (alemã), "EAQF - 
Evaluation d'Aptitude Qualité Fournisseurs" (francesa) e "AVSQ - Associazone Nazionale Fra Industrie Automobilistiche Valutazione Sistemi Qualità" (italiana). Então, surge a ISO/TS 16949 para alinhar todas essas normas numa só, evitando múltiplas auditorias de certificação e promovendo uma abordagem comum para um sistema de gestão da qualidade das organizações de produção automotiva e peças de reposição pertinentes, tornando a especificação técnica do padrão de qualidade da indústria automotiva mais utilizada em todo o mundo (ROCHA et al., 2009). Além disso, é a especificação técnica que define os requisitos de um SGQ para projeto, desenvolvimento, produção e, quando pertinente, instalação e serviços relacionados. Fora isso, suas diretrizes contêm práticas, exemplos, ilustrações e explicações recomendadas pelas indústrias automotivas. Entretanto, essa especificação técnica não possui finalidade contratual ou de certificação, daí a importância de se observar os princípios e requisitos das normas ISO 9001 e 9004, presentes em grande parte das seções desta Especificação Técnica.

\subsection{A Maturidade de Processo}

No ambiente organizacional, maturidade é a "extensão em que o processo é explicitamente definido, gerenciado, medido, controlado e eficaz" (SIQUEIRA, 2009). Assim, as organizações maduras agem de modo sistemático e atingem seus objetivos de qualidade de forma consistente e eficiente através da coleta de dados que são usados para analisar, controlar, prever e planejar seu desempenho. Para Ferreira (2009), todas as empresas passam por níveis de maturidade e cada mudança nos processos deve servir como aprendizado, mesmo para empresas sem modelo aplicado em seus processos. Por meio do nível de maturidade de uma empresa é possível identificar o grau que ela aplica às suas práticas de PDP.

Segundo Siqueira (2009), ao se utilizar um modelo de maturidade de processos, tem-se uma abordagem disciplinada do processo que possibilita a identificação dos pontos críticos e a definição de ações de melhoria que devem estar alinhadas com os objetivos estratégicos da organização e consistentes com o estágio de maturidade de seus processos. 
O conceito de níveis de maturidade, primeiramente proposto por Crosby, em 1979, estabelecia cinco estágios com base nas práticas adotadas, posteriormente adaptados pelo SEI, surgindo então outros modelos a partir de 1986. Assim, foi desenvolvido o CMMI que, com algumas similaridades com a norma ISO 9000:2000, vem, desde então, tendo crescente utilização no meio empresarial, pois estabelece metas de melhoria de processos internos e padrão para fornecedores, com significativas melhorias de desempenho também nas áreas de custo, prazos, qualidade, satisfação de clientes e retorno sobre investimentos, sendo perfeitamente adequado para a mensuração do nível de maturidade do PDP das organizações de produção automotiva (QUINTELLA e ROCHA, 2006). Com o passar do tempo, as denominações anteriores do CMMI foram substituídas pelo título "CMMI para Desenvolvimento" (CMMI-DEV) com o objetivo de refletir verdadeiramente a ampla integração de conhecimento e a aplicação do modelo nas organizações, fornecendo uma solução integrada e abrangente para as atividades do desenvolvimento e manutenção aplicada a produtos e serviços (SEI, 2006).

No modelo CMMI, "utilizam-se níveis para descrever um caminho evolutivo recomendado para uma organização que deseja melhorar os processos utilizados para desenvolver e manter seus produtos e serviços" (SEI, 2006), os quais são assim resumidos:

Nível 1 - Inicial: O sucesso depende da competência e do heroísmo das pessoas e não do uso dos processos comprovados.

Nível 2 - Gerenciado: Os projetos da organização têm a garantia de que os processos são planejados e executados de acordo com uma política e são monitorados, controlados e revisados, além de serem avaliados para verificar sua aderência em relação à descrição de processo.

Nível 3 - Definido: Os processos são bem caracterizados e entendidos e são descritos em padrões, procedimentos, ferramentas e métodos, cujo conjunto é estabelecido e melhorado ao longo do tempo, adaptados a partir do conjunto de processos-padrão da organização para se ajustar a um projeto específico ou a uma unidade organizacional.

Nível 4 - Gerenciado Quantitativamente: A organização e os projetos estabelecem objetivos quantitativos, baseados nas necessidades dos clientes, para 
qualidade e para desempenho do processo, entendidos em termos estatísticos e gerenciados ao longo da vida dos processos.

Nível 5 - Em Otimização: Uma organização melhora continuamente seus processos com base no entendimento quantitativo das causas comuns de variação inerentes ao processo, com foco na melhoria contínua do desempenho de processo por meio de melhorias incrementais e inovadoras de processo e de tecnologia, estabelecendo objetivos quantitativos de melhoria de processo, os quais são continuamente revisados e utilizados como critérios na gestão de melhoria de processo.

Para cada nível de maturidade, além das áreas de processos (PAs) identificadas, existem metas específicas (SGs) e metas genéricas (GGs) que devem ser alcançadas pelos processos de planejamento e implantação da organização. $O$ modelo CMMI é composto por 22 PAs, distribuídas pelos cinco níveis. Visando a avaliar a compatibilidade da ISO/TS 16949 até o nível 2 do CMMI e considerando a representação estagiada, são conceituadas apenas as sete PAs que estarão envolvidas nessa avaliação, assim resumidas:

1) Gestão da Configuração (CM): visa a garantir a manutenção integrada de produtos do trabalho, realizada por meio da identificação e/ou controle da configuração, além do balanço das atividades e auditorias.

2) Medição e Análise (MA): tem como objetivo principal o desenvolvimento e a manutenção da capacidade de mensurar, dando suporte às necessidades de informação para gestão.

3) Monitoramento e Controle de Projeto (PMC): objetiva proporcionar maior clareza e controle para os status do projeto, facilitando a visibilidade em eventuais desvios.

4) Planejamento de Projeto (PP): visa o estabelecimento e à manutenção de planos que definam as atividades de projeto.

5) Garantia de Qualidade de Processo e Produto (PPQA): tem por objetivo suprir a equipe de projeto e gerência quanto aos processos e produtos associados. 
6) Gestão de Requisitos (REQM): visa a dar suporte ao gerenciamento de requisitos de produtos e componentes, identificando inconsistência entre os planos, requisitos e produtos do trabalho de projeto.

7) Gestão de Contrato com Fornecedores (SAM): gerencia a aquisição de produtos de fornecedores, selecionando-os e determinando os modelos a serem aplicados bem como a execução do contrato com os mesmos.

\section{METODOLOGIA DE PESQUISA}

Após a revisão bibliográfica sobre os temas envolvidos, iniciou-se a associação dos termos contidos nas duas abordagens delimitadas para o estudo. Para identificar uma possível associação entre o CMMI-DEV 1.2 e a ISO/TS 16949, primeiramente, identificou-se a atuação dos dois modelos, desde o nível sistêmico até o nível operacional. A segmentação, em função do nível de atuação de ambos os modelos, estão representados na Figura 1, sendo a mais abrangente, chamada de dimensão, referente às Seções da ISO e às Áreas de Processo do CMMI. A segunda, nomeada como temas, refere-se às cláusulas da ISO e às práticas genéricas no modelo CMMI, em que são abordadas as ações macro nas duas abordagens. O último e mais detalhado, chamado de ações, refere-se às descrições das cláusulas da ISO e às metas específicas do CMMI, em que são tratadas as atividades a serem realizadas na empresa, quando verificadas com cada uma das abordagens. 
Figura 1 - Segmentação do Método da Pesquisa

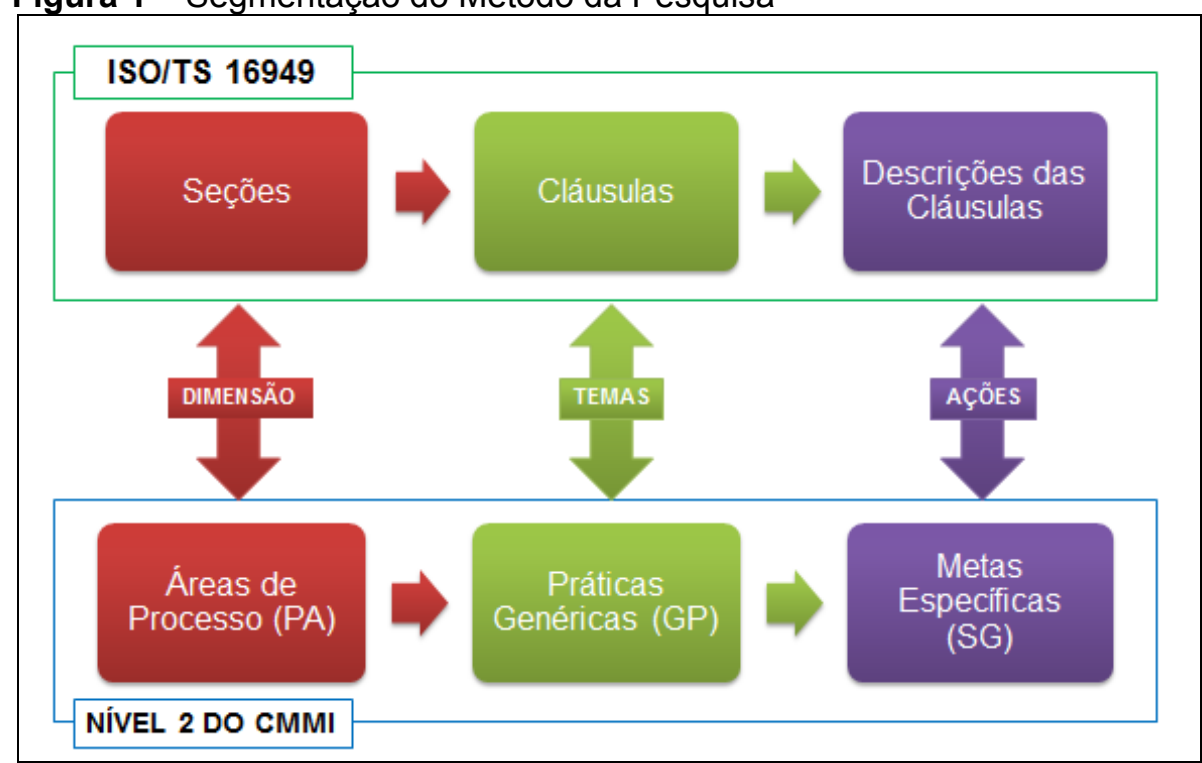

Fonte: Elaborado pela autora

Sendo assim, iniciou-se a comparação entre as seções da ISO/TS 16949 e as PAs do CMMI. Das seções da ISO/TS 16949, apenas as seções 4, 5, 6, 7 e 8 foram delimitadas para o estudo, em função das seções 1,2 e 3 corresponderem às generalidades da norma, enquanto que as demais correspondem aos requisitos necessários para a implantação e manutenção do $S G Q$, o qual é útil nesse projeto em função de demonstrar as ações necessárias que melhoram processos das empresas que a aderirem.

Posteriormente, delimitou-se as PAs do CMMI-DEV 1.2 correspondentes ao nível 2 de maturidade, em função das conclusões encontradas nos estudos de Fransozi (2010), Lisboa (2010) e Vaz (2010), os quais constataram que as empresas de nível 2 de maturidade já estariam aptas a se certificarem, mantendo essa certificação por longo prazo, caso esse nível estivesse bem estabelecido. Isso significa que, provavelmente, a ISO apresente uma maior correlação até esse nível de avaliação do CMMI e nos demais níveis ela possua apenas correlações pontuais, a serem verificadas em trabalhos futuros.

Buscando facilitar a visualização e análise dos dados, foi necessária a elaboração de uma matriz de parentesco. A forma de identificar se os itens possuíam ou não alguma correlação foi por meio da escala 0, 30, 60 e 100 para o fator de confiabilidade, proposto por Mutafelija e Stromberg (2009). Cada item era

Revista Produção Online, Florianópolis, SC, v.14, n. 2, p. 679-702, abr./jun. 2014. 
verificado, considerando uma associação com aqueles que apresentassem 100. Esse desenvolvimento foi realizado baseando-se apenas na análise da revisão bibliográfica dos dois modelos e dos termos neles contidos.

\section{ANÁLISE DOS RESULTADOS}

A Figura 2 apresenta as PAs que devem ser atendidas no CMMI-DEV para que a empresa seja reconhecida com maturidade nível 2. Também mostra quais seções da ISO têm parentesco com determinadas áreas de processo do CMMI.

Figura 2 - Associação entre PA do CMMI e Seções da ISO/TS 16949

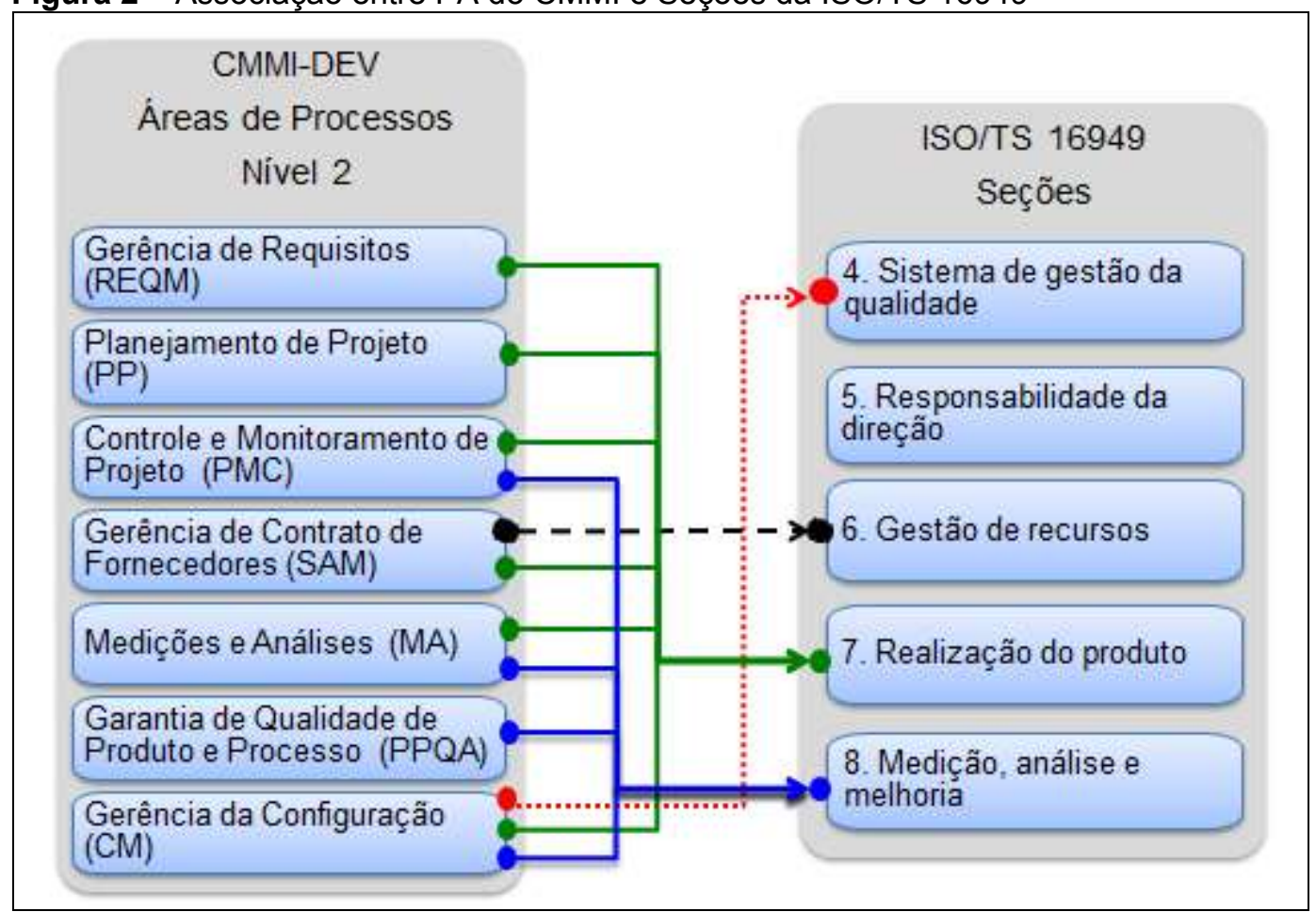

Fonte: Elaborado pela autora

Nesta figura é possível identificar que, buscando atingir o nível 2 de maturidade do CMMI-DEV 1.2, as seções 4, 7 e 8 da ISO/TS 16949 foram aquelas nas quais se identificou determinado grau de parentesco em relação ao CMMI.

A partir do término da avaliação sistêmica entre as duas abordagens, denominada como uma avaliação das dimensões de ambas tem-se uma 
ramificação das duas abordagens, denominada de itens que descrevem temas da situação, expressos tanto no CMMI-DEV 1.2 como na ISO/TS 16949.

\subsection{Avaliação Operacional}

As Metas Genéricas (GGs) são as que começam a remeter a uma avaliação a nível operacional no CMMI, atingindo todas as áreas de processo. O desdobramento da meta genérica "GG2 - Institucionalizar Processo Gerenciado" aborda em maior nível de detalhes o parentesco das Práticas Genéricas (GPs) do nível 2 de maturidade do CMMI, representação estagiada, com as cláusulas da ISO/TS. Assim, na Figura 3 é possível identificar as cláusulas da ISO/TS 16949 em que se identificou determinado grau de parentesco em relação ao CMMI.

Figura 3 - Associação entre GPs do CMMI e Cláusulas da ISO/TS 16949

\begin{tabular}{|l|l|l|}
\hline \multicolumn{1}{|c|}{ CMMI-DEV } \\
Práticas Genéricas (GP) \\
Nivel 2
\end{tabular}

Fonte: Elaborado pela autora

Desta forma constata-se que a ISO/TS 16949:2004 atende apenas parcialmente às práticas assim estabelecidas nas áreas de processo do nível 2 de

Revista Produção Online, Florianópolis, SC, v.14, n. 2, p. 679-702, abr./jun. 2014. 
maturidade do CMMI-DEV 1.2, por haver prática genérica destas PAs que não são contempladas na norma em sua totalidade, sendo essa a GP 2.7 "Identificar e Envolver Stakeholders Relevantes".

Após a finalização da avaliação operacional entre as duas abordagens, denominada como uma avaliação dos temas de ambas, o trabalho tem como sequência a abordagem da última ramificação, a qual foi denominada de elementos que descrevem as ações das atividades, expressas tanto no CMMI-DEV 1.2 como na ISO/TS 16949.

\subsection{Correlação das Atividades Avaliadas}

Com base nos dados resultantes das comparações previamente apresentadas, é possível seguir o detalhamento no nível das ações. Essa comparação ocorreu baseando-se na experiência da autora, considerando as literaturas consultadas sobre CMMI-DEV 1.2 e ISO/TS 16949.

As análises são realizadas pelas associações existentes entre as descrições das cláusulas da ISO/TS 16949:2004 e as Práticas Específicas (SPs) do CMMI-DEV 1.2, correspondentes à avaliação de nível 2 de maturidade. A seguir, os itens foram separados em PAs e subdivididos em Metas Específicas (SGs), para facilitar a compreensão dos parentescos entre as ações das descrições das Cláusulas (da ISO) versus Práticas Específicas (do CMMI). Entretanto, é importante salientar que para uma SP ser relacionada com a ISO/TS é necessário que sua prática genérica possua parentesco com a ISO.

Com isso, para realizar a leitura de verificação do atendimento da PA, conforme a aplicação do CMMI, do ponto de vista da SG, as SPs da mesma PA devem ser verificadas na empresa analisada. Por exemplo: do ponto vista da SG 2.1 "Estabelecer uma política organizacional", a empresa "Obtém o entendimento dos requisitos (SP 1.1)", "Obtém comprometimento com os requisitos (SP 1.2)", "Gerencia mudanças nos requisitos (SP 1.3)", "Mantêm rastreabilidade bidirecional dos requisitos (SP 1.4)" e "Identifica inconsistências entre produtos de trabalho (SP 1.5)"; e sucessivamente para todas as SGs necessárias ao nível 2 de maturidade. Assim, se todas as SGs em todas as PAs (na representação estagiada) forem verificadas, a empresa possuirá o nível 2 de maturidade em seus processos. Revista Produção Online, Florianópolis, SC, v.14, n. 2, p. 679-702, abr./jun. 2014. 
Seguindo a proposta do CMMI, deveria ser realizado a análise de parentesco com a ISO, identificando as cláusulas para cada relação SG com SP. Entretanto, a análise desse trabalho dá-se no âmbito de PA, salvaguardando os resultados, conforme proposto na sequência.

Para fazer as correlações, iniciou-se pela PA "Gerência de Requisitos (REQM)", composta por apenas uma meta específica "SG1 Gerenciar Requisitos" que é descrita para manter um conjunto de requisitos aprovado e atualizado durante o ciclo de vida do projeto, executando as atividades para gerência de mudanças de requisitos para o relacionamento e na identificação de inconsistências entre os requisitos (planos de projeto e produtos de trabalho) e para implementar ações corretivas. Deste modo, pôde-se observar que a Seção 7 "Realização do Produto" corresponde expressivamente com o CMMI-DEV 1.2 correlacionado com as cláusulas: 7.1.1 "Planejamento da realização do produto - Suplemento", 7.2.2 "Análise crítica dos requisitos relacionados ao produto", 7.2.3 "Comunicação com o cliente", 7.3.2.1 "Entradas de projeto do produto" e 7.5.3 "Identificação e rastreabilidade". Ao avaliar as correlações apresentadas entre a PA "Gerência de Requisitos (REQM)" e as cláusulas da norma ISO/TS 16949, constata-se que ambas tratam da manutenção e definição dos requisitos dos produtos, determinando que, após aprovados, a empresa deve ter capacidade de atendê-los cumprindo a necessidade de se manter registros de resultados, análises críticas e resultados das análises. Desta forma, a norma atende à área de processo em sua totalidade.

A segunda PA relacionada, "Planejamento de Projeto (PP)", é composta por três metas específicas: "Estabelecer Estimativas (SG1)", "Elaborar um Plano de Projeto (SG2)" e "Obter Compromisso com o Plano (SG3)". Entretanto, para encontrar as correspondências existentes com esta área de processo, optou-se por realizar a análise com a Seção 7 "Realização do Produto" da ISO/TS 16949, por possuir as descrições nas cláusulas referentes ao planejamento do produto. Dessa forma, observou-se que as SGs dessa PA não estão completamente atendidas pela ISO/TS 16949:2004. Por isso, constata-se que a norma ISO/TS 16949 não apresenta todas as etapas necessárias para completar o nível 2 de maturidade do CMMI-DEV 1.2. Além disso, ratifica-se que para o planejamento e realização do produto é necessário identificar e envolver Stakeholders relevantes para, com isso, 
obter seu o comprometimento com o plano conciliando a carga de trabalho, como previsto nas práticas "SP 3.2 Conciliar carga de trabalho e recursos" e "SP 3.3 Obter comprometimento das partes interessadas com o plano".

Em terceiro lugar, foi feita a análise da PA "Controle e Monitoramento do Projeto (PMC)", que é composta por duas SGs: Monitorar o Projeto em Relação ao Plano (SG1) e Gerenciar Ações Corretivas até sua Conclusão (SG2). Dessa análise, pôde-se verificar que as cláusulas que mais se relacionam com a meta específica "SG1 Monitorar o Projeto em Relação ao Plano" são: 7.3.2.1 "Entradas de projeto do produto", 7.3.2.3 "Características especiais", 7.3.4.1 "Monitoramento", 7.5.1.1 "Plano de controle" e 7.3.2.3 "Características especiais".

A quarta PA, "Gestão de Contrato com Fornecedores (SAM)", tem correspondências existentes com diversas seções da ISO/TS 16949, principalmente por ser a mais relevante para a ISO e por abordar a inclusão com fornecedores. Esta é composta por duas SGs: "Estabelece Contratos com Fornecedores (SG1)" e "Cumpre Contratos com Fornecedor (SG2)". Da análise, observou-se que as SGs da PA "Gestão de Contrato com Fornecedores (SAM)" não estão completamente atendidas pela ISO/TS 16949. Sendo assim, determina-se que a norma não apresenta as etapas necessárias para completar o nível 2 de maturidade do CMMIDEV 1.2.

A quinta PA analisada, "Medição e Análise (MA)", é composta por duas SGs: "Alinhar Atividades de Medição e Análise (SG1)" e "Fornecer Resultados de Medição (SG2)". Desta análise, verificou-se que a meta SG2 não está correlacionada por completo com as cláusulas da ISO/TS 16949, não atendendo totalmente aos critérios do nível 2 de maturidade previsto no CMMI-DEV 1.2.

A sexta PA "Garantia de Qualidade de Produto e Processo (PPQA)" é composta por duas SGs: "Avalia Objetivamente Processos e Produtos de Trabalho (SG1)" e "Fornece Visibilidade (SG2)". Da análise, pôde-se constatar que a Seção 8 "Medição, análise e melhoria" da ISO/TS 16949 foi aquela que mais obteve itens relevantes correlacionados com as SGs e que a SG2 é completamente atendida pela ISO/TS 16949. Na identificação das correlações, ficam evidentes as ligações com as cláusulas da Seção 8 "Medição, análise e melhoria do processo de qualidade" nos produtos. Essas cláusulas mostram a prática de planejamento e 
implementação de processos visando o monitoramento, medição, análise e melhoria que demonstram a conformidade do produto, assegurando ao SGQ melhoria contínua e eficácia do mesmo e, de forma satisfatória, englobando o nível 2 de maturidade do CMMI-DEV 1.2 para esta meta específica.

Por fim, a sétima PA "Gerência da Configuração (CM)", que estabelece e mantém íntegros os produtos de trabalho. Para tanto, esta é composta de três SGs: "Estabelece Baselines (SG1)", "Acompanha e Controla Mudanças (SG2)" e "Estabelece Integridade (SG3)". A partir desta comparação, pôde-se identificar que todos os aspectos relacionados a estas metas são contempladas na ISO/TS 16949.

\subsection{Considerações Finais}

Alguns aspectos afetados pela falta de comunicação em um PDP são salientados pelos autores Harrington, Esseling e Nimwegen (1997), sendo eles: o acúmulo de procedimentos e de operações de processamento de dados; a existência de semelhantes documentos realizados em diferentes setores da empresa; o recebimento de informação em excesso; o não recebimento de informação; a verificação de informações acumuladas, mesmo após não serem mais úteis para o trabalho desenvolvido no presente período; e o excesso, ou a falta, de interações durante o trabalho.

Visando a estratificar e consolidar as informações das análises do relacionamento entre a ISO/TS e o CMMI, foram elaboradas algumas análises. Uma delas é por meio do quadro que mostra a quantidade de práticas do CMMI-DEV que foram atendidas, ou não, pela ISO/TS, agrupadas por área de processo, como apresenta o Quadro 1. 
Quadro 1 - Número de práticas do CMMI atendidas pela ISO/TS

\begin{tabular}{|c|l|c|c|}
\hline $\begin{array}{c}\text { PA } \\
\text { (sigla) }\end{array}$ & \multicolumn{1}{|c|}{ Área de Processo (PA) } & $\begin{array}{c}\text { Práticas } \\
\text { Atendidas } \\
\text { pela ISO/TS }\end{array}$ & $\begin{array}{c}\text { Práticas Não } \\
\text { Atendidas } \\
\text { pela ISO/TS }\end{array}$ \\
\hline REQM & Gerência de Requisitos & 5 & 0 \\
\hline PP & Planejamento de Projeto & $\mathbf{1 0}$ & $\mathbf{4}$ \\
\hline PMC & Controle e Monitoramento de Projeto & $\mathbf{4}$ & $\mathbf{6}$ \\
\hline SAM & Gestão de Contrato com Fornecedores & 7 & 1 \\
\hline MA & Medição e Análise & 6 & 2 \\
\hline PPQA & $\begin{array}{l}\text { Garantia da Qualidade de Processo e } \\
\text { Produto }\end{array}$ & 4 & 0 \\
\hline CM & Gerência da Configuração & 7 & 0 \\
\hline
\end{tabular}

Fonte: Elaborado pela Autora

Pela análise gráfica (Gráfico 1), que mostra o grau percentual de cobertura da ISO/TS para cada PA do CMMI-DEV, constata-se que, principalmente, as PAs "Planejamento de Projeto (PP)" e "Controle e Monitoramento de Projeto (PMC)" têm itens descobertos pela ISO. Vale ressaltar que ambos estão relacionados com uma etapa importante no PDP, referente ao projeto do produto, etapa inicial neste processo.

Gráfico 1 - Porcentagem de Práticas do CMMI-DEV 1.2 atendidas pela ISO/TS 16949

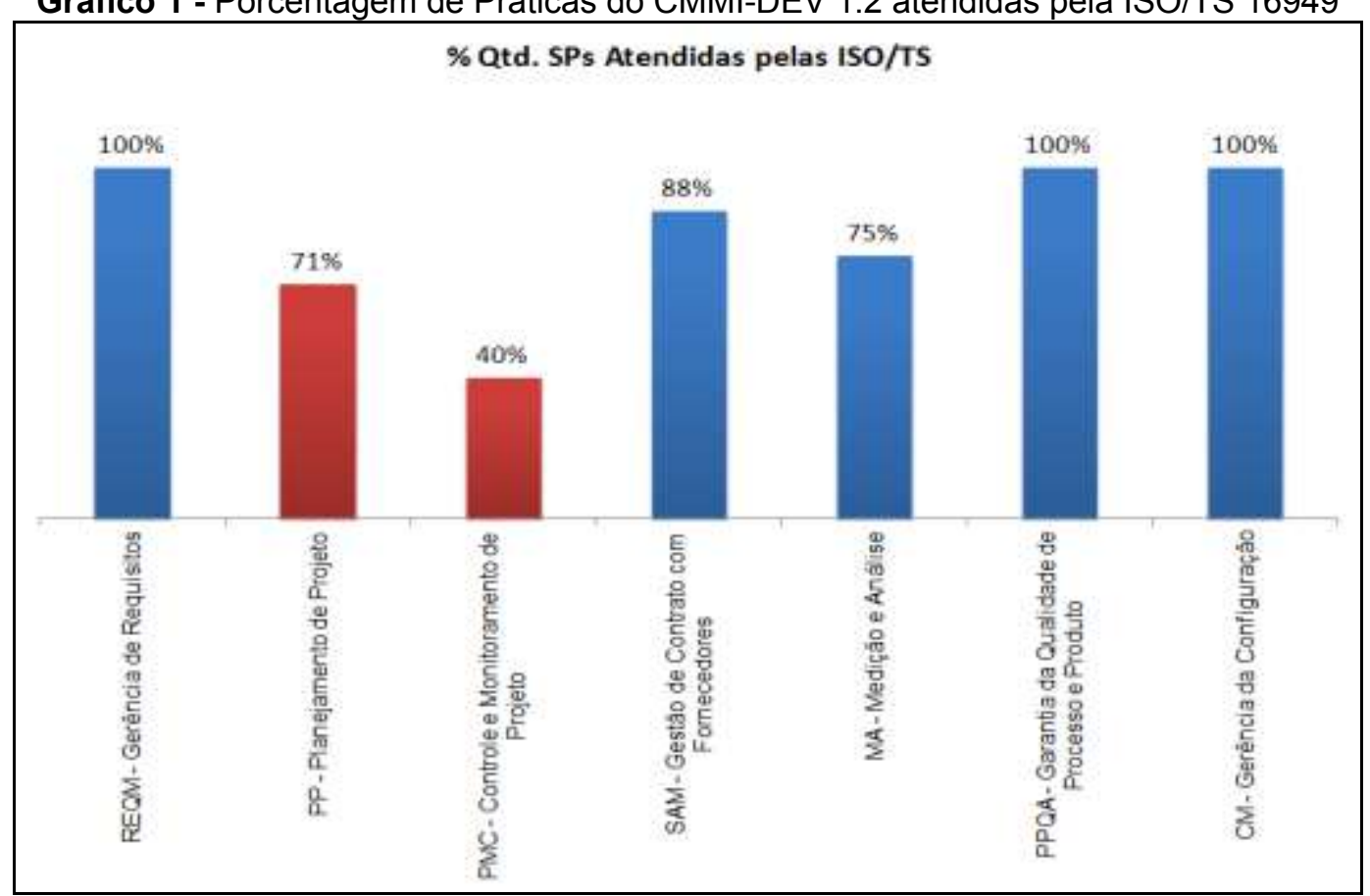

Fonte: Elaborado pela autora

Detalhando as práticas específicas das duas PAs que são menos atendidas pela ISO/TS 16949, constata-se que para satisfazer as atividades ali descritas, é

Revista Produção Online, Florianópolis, SC, v.14, n. 2, p. 679-702, abr./jun. 2014. 
necessário atender a prática genérica "GP 2.7 Identificar e Envolver Stakeholders Relevantes", que não possui correlação com nenhuma cláusula da ISO/TS, ou seja, todas as práticas específicas que identificam e/ou envolvem as partes interessadas (Stakeholders) em suas atividades ficaram prejudicadas. Conforme a própria definição do termo no CMMI-DEV, Stakeholders são grupos ou indivíduos afetados pelo resultado de uma tarefa ou, de algum modo, responsáveis por ela como: membros do projeto, clientes, usuários finais, entre outros (SEI, 2006). Todavia, a ISO/TS não prevê identificação de forma estruturada das partes interessadas, apenas ao longo dos processos estabelece correlação com alguns Stakeholders, como clientes, por exemplo.

Ao identificar as SPS não atendidas pela ISO/TS, as quais se referem às metas específicas "SG2 Elaborar um Plano de Projeto" e "SG3 Obter Comprometimento com o Plano", conclui-se que a norma ISO/TS permite que empresas possuam a sua certificação mesmo que não atinjam de forma robusta e adequada a elaboração de um plano de projeto, bem como não tenham o comprometimento com o plano, diferentemente do que é previsto para o nível 2 de maturidade da abordagem do CMMI-DEV.

A ISO/TS não avalia os itens de plano de projeto, no entanto, os autores Rozenfeld et al. (2006) e Clark e Weelwright (1993) mostram esta etapa de projeto de forma segregada dentro do PDP, representando-a numa das mais importantes neste contexto, o que significa que planejar essa etapa é um ponto fundamental. Além disso, ressalta-se, também, a importância da comunicação que vise a integração, esta enfatizada por autores, como Hartley (1998), como um dos principais fatores para se desenvolver produtos bem sucedidos e que se refere ao envolvimento e à colaboração coletiva.

O problema pode se estender em todas as fases do ciclo de vida do produto, visto que a ISO/TS não determina o que deveria ter sido feito, por meio da identificação dos tipos de pessoas e funções, a descrição, relevância e grau de interação de todas as partes interessadas nas atividades especificadas no plano. Por sua vez, desta forma não se obtém a compreensão mútua, comprometimento e desempenho dos indivíduos.

Revista Produção Online, Florianópolis, SC, v.14, n. 2, p. 679-702, abr./jun. 2014. 
Ao verificar as SPs das metas específicas "SG1 Monitorar o Projeto em Relação ao Plano" e "SG2 Gerenciar Ações Corretivas até sua Conclusão" que não têm parentesco identificado com a ISO/TS, pode-se afirmar que isto acarretaria uma revisão periódica de riscos atualizados do projeto que, mesmo mitigados, certamente não compreenderiam todos os aspectos relevantes, como previsto na norma ISO/TS. Além disso, diferentemente do CMMI, a norma ISO/TS não prevê que as partes interessadas não terão suas atividades monitoradas, a fim de garantir que ocorram as interações de forma apropriadas e que assegurem a execução do plano de projeto. Igualmente, condução de revisões de progresso, análise de questões críticas, bem como a implementação de ações corretivas para saná-las não ocorrerão conforme o plano, gerando desempenho inadequado pela não determinação de ações necessárias para tratar as situações críticas, visto que elas não serão identificadas adequadamente ou de forma correta, são outros fatores relatados no CMMI-DEV que não são discutidos adequadamente na ISO/TS.

Com base no exposto, a principal consequência do não atendimento dessas práticas é que, com frequência, serão extrapolados os orçamentos do plano, bem como os prazos não serão cumpridos, embora até se possa chegar a produtos que funcionem (SEI, 2006).

Isso mostra que a utilização apenas da abordagem ISO/TS 16949 por si só, não é suficiente. O ideal é que sejam adotadas outras abordagens que possam dar suporte, como o CMMI-DEV, que já no nível 2 de maturidade garante que os processos sejam planejados e executados em consonância com os itens considerados fundamentais para o adequado desempenho de um PDP, conforme descritos acima. Desta forma, propõe-se que se empreguem pessoas experientes que possuam recursos adequados para produzir saídas controladas. Além disso, que sejam envolvidas as partes interessadas relevantes, mantendo os planos monitorados, controlados e revisados, de forma que mantenham sua aderência em relação ao processo descrito (SEI, 2006). 


\section{CONCLUSÃO E RECOMENDAÇÕES}

Considerando que o objetivo foi identificar a associação existente entre a ISO/TS 16949, norma de gestão da qualidade aplicável às organizações de produção automotiva, e as variáveis avaliadas pelo CMMI-DEV 1.2 para até ao nível 2 de maturidade nas empresas, pode-se afirmar que o estudo fez a associação de itens de mesmo nível entre as duas abordagens. Primeiramente foram comparadas as seções da ISO/TS 16949 com as áreas de processo do CMMI-DEV. Como resultado da comparação entre as cláusulas da ISO/TS 16949, constatou-se que a prática genérica do CMMI-DEV "GP 2.7 Identificar e Envolver Stakeholders Relevantes" não é avaliada pela ISO/TS.

Em seguida, ao comparar as SPs do CMMI-DEV com as descrições das cláusulas da ISO/TS, constatou-se que as práticas específicas "SP 2.6 Planeja o Envolvimento das Partes Interessadas", "SP 2.7 Estabelece o Plano do Projeto", "SP 3.2 Concilia Carga de Trabalho e Recursos" e "SP 3.3 Obtém Comprometimento com o Plano" referente à área de processo "Planejamento do Projeto (PP)" e as práticas específicas "SP 1.3 Monitora Riscos do Projeto", "SP 1.5 Monitora o Envolvimento das Partes Interessadas", "SP 1.6 Conduz Revisões de Progresso", "SP 1.7 Conduz Revisões de Marco", "SP 2.1 Analisa Questões Críticas" e "SP 2.2 Implementa Ações Corretivas" relativa à área de processo "Controle e Monitoramento do Projeto (PMC)" também não são avaliadas pela ISO/TS.

Conclui-se, com os resultados gerais desse trabalho, que, quando a ISO/TS certifica uma empresa, se a mesma fosse avaliada com o CMMI-DEV, isso não representa que a mesma atingiria ao nível 2 de maturidade de forma completa. Em detalhes, os itens que a ISO/TS menos avalia referem-se ao "Planejamento do Projeto e Controle" e "Monitoramento do Projeto". O impacto que a falta dessa verificação poderia desencadear para aquelas empresas que não realizam essas atividades, mas que deveriam ter a meta de executá-las como diagnóstico, é que isso poderia causar retrabalhos e modificações não planejadas ao longo do desenvolvimento de produto.

Considerando que esse trabalho comparou a ISO/TS 16949 com os itens avaliados pelo CMMI até o nível 2 de maturidade, sugere-se como trabalhos futuros 
que as associações avancem para os níveis 3, 4 e 5 de maturidade pelo CMMI-DEV. Afinal, pode ser que a ISO/TS não considere todos os itens contidos na avaliação do CMMI-DEV para o nível 2, mas isso não significa que ela não avalie alguns itens isolados contidos nos níveis superiores a este.

\section{REFERÊNCIAS}

ABNT, Associação Brasileira de Normas Técnicas. NBR ISO/TS 16949:2004. Sistema de Gestão da Qualidade - Requisitos particulares para aplicação da ABNT NBR ISO 9001:2000 para organizações de produção automotiva e peças de reposição pertinentes. Rio de Janeiro, 2004.

.CB-25, Comitê Brasileiro da Qualidade. Disponível em:

<http://www.abntcb25.com.br/> Acesso em: 20 set. 2010.

ALMEIDA, Marcelo H.; CATEN, Carla S. T.; GUTTERRES, Mariliz. Evaluating ISO 9001:2000 Certified and Non-Certified Organizations in Brazilian Leather-Footwear Chain. Brazilian Journal of Operations \& Production Management, v. 6, n. 2, p. 51-73, dez. 2009.

BAXTER, Mike; Projeto de produto: Guia Prático para o Desenvolvimento de Novos Produtos. São Paulo: Blucher, 1998.

CLARK, K.B.; FUJIMOTO, T. The power of product integrity. Harvard business review, p. 107-118, nov. 1990.

CLARK, Kim B.; WHEELWRIGTH, Steven C.; Managing New Product and Process Development, Free Press, New York, 1993.

DESCHAMPS; J.; NAYAK, P.R. Produtos Irresistíveis: como operacionalizar um fluxo perfeito de produtos do produtor ao consumidor. São Paulo: Makron Books, 1997.

FERREIRA, Eduardo D. Correlação canônica entre as características organizacionais e os níveis de processos no desenvolvimento de produto. 2009. 162 f. Dissertação (Mestrado Engenharia de Produção e Sistemas), Pontifícia Universidade Tecnológica do Paraná, Curitiba, 2009.

FRANZOSI, Ligia O. Maturidade do PDP e certificação da qualidade: Coerência Encontrada no Setor de Alimentos de Curitiba. 2010. 135 f. Dissertação (Mestrado em Engenharia) - Programa de Pós-graduação em Engenharia Mecânica e de Materiais, Universidade Tecnológica Federal do Paraná, Curitiba, 2010.

FUNDAÇÃO CARLOS ALBERTO VANZOLINI. Perguntas mais frequentes sobre a certificação ISO/TS 16949:2002. Boletim técnico. 2011. 
HARRINGTON, H. J.; ESSELING, E. K.; NIMWEGEN, H.V. Business process improvement - workbook: documentation, analysis, design, and management of business process improvement. New York: McGraw-Hill, 1997.

HARTLEY, J. R. Engenharia simultânea. Porto Alegre: Bookman, 1998.

KITSON, David H.; VICKROY, Robert; WALZ, John; WYNN, Dave. An Initial Comparative Analysis of the CMMI Version 1.2 Development Constellation and the ISO 9000 Family. Special Report CMU/SEI, SR 005, mar. 2009. Disponível em: < http://www.sei.cmu.edu/library/abstracts/reports/09sr005.cfm>. Acesso em: 30 jul. 2011.

LISBOA, Fabio C. Maturidade do processo de desenvolvimento de produto e certificação da qualidade: coerência encontrada no polo de Duas Rodas de Manaus. 2010. 134 f. Dissertação (Mestrado em Engenharia) - Programa de Pósgraduação em Engenharia Mecânica e de Materiais, UTFPR, Manaus, 2010.

MELLO, Carlos H. P. et al. ISO 9001-2008: sistema de gestão da qualidade para operações. 1.ed. Atlas, 2009.

MELLO, Esequiel B. Processo de desenvolvimento do produto em empresas de uma cadeia automotiva: um estudo comparativo. 2008. 123 f. Dissertação (Mestrado em Administração) - Programa de Pós-Graduação em Administração, Universidade de Caxias do Sul, Caxias do Sul, 2008. Disponível em: $<$ http://tede.ucs.br/tde arquivos/5/TDE-2008-08-27T062253Z208/Publico/Dissertac ao\%20Esequiel\%20de\%20Mello.pdf>. Acesso em: 18 dez. 2011.

MUTAFELIJA, Boris; STROMBERG, Harvey. Process Improvement with CMMI® v1.2 and ISO Standards, 1 ed. , New York: CRC Press, 2009.

OAKLAND, John S., Gerenciamento da qualidade total TQM. São Paulo: Nobel, 2007.

PAASHUIS, V.; BOER, H. Organizing for concurrent engineering: an integration mechanism framework. Integrated manufacturing systems. v. 8, n. 2, p. 79-89, 1997. http://dx.doi.org/10.1108/09576069710165765

PEKOVIC, Sanja; GALIA Fabrice, From quality to innovation: Evidence from two French Employer Surveys, Technovation, v. 29, n.12, p. 829-842, dez. 2009. http://dx.doi.org/10.1016/j.technovation.2009.08.002

PINO, Francisco J. ; BALDASSARRE, Maria T.; PIATTINI, Mario; VISAGGIO, Giuseppe. Harmonizing maturity levels from CMMI-DEV and ISO/IEC 15504. Journal of Software Maintenance and Evolution: Research and Practice, v. 22, n. 4, p. 279-296, jun. 2010. 
QUINTELLA, Heitor L. M. de M.; ROCHA Henrique M. Avaliação da Maturidade do Processo de Desenvolvimento de Veículos Automotivos. Revista Gestão e

Produção. v.13, n.2, p.297-310, maio/ago.2006.

. Nível de maturidade e comparação dos PDPs de produtos automotivos.

Produção, v. 17, n. 1, p. 199-217, jan. - abr., 2007. http://dx.doi.org/10.1590/S010365132007000100014

RISSATO, Ilson L. Implantação coletiva de sistema de qualidade ISO9001. Revista Eletrônica de Educação e Tecnologia do SENAI-SP, v.3, n.7, 2009. Disponível em: < http://revistaeletronica.sp.senai.br> Acesso em: 30 ago. 2010.

ROCHA, Beatriz R. D.; BARRERA, Francisco C. E.; PADILLA, Horacio L. Knowledge Capitalization in the Automotive Industry Using an Ontology Based on the ISO/TS 16949 Standard. In: Electronics, Robotics And Automotive Mechanics Conference, 2009. CERMA '09. IEEE Computer Society, p.100-106, 22-25 set. 2009.

RODRIGUES, Ronaldo. C. O que leva uma empresa a perder seu certificado? 2008. Disponível em: <http://www.oficinadanet.com.br/artigo/1283/o que leva uma empresa a perder seu certificado>. Acesso em: 16 mar. 2012.

ROZENFELD, Henrique et al. Gestão de desenvolvimento de produto: uma referência para melhoria de processo. São Paulo: Editora Saraiva, 2006.

RUZEVICIUS, J., The study of quality certification system of Lithuania. Engineering Economics, v. 02, p. 78-84, abr. 2008.

SEI, SOFTWARE ENGINEERING INSTITUTE. CMMI para Desenvolvimento: Melhoria de Processos Visando Melhores Produtos (CMMI-DEV).Ed. Carnegie Mellon. Pittsburgh, PA, ago. 2006.

SIQUEIRA, Jairo. O Modelo de Maturidade de Processos: como maximizar o retorno dos investimentos em melhoria da qualidade e produtividade. Instituto Brasileiro de Qualidade Nuclear - IBQN, 2009. Disponível em: <http://www.ibqn.com.br/htm ar tigos links/Jairo Siqueira Artigo Modelo\%20de\%20Maturidade.pdf>. Acesso em: 04 abr. 2010.

SLACK, Nigel; CHAMBERS, Stuart; JOHNSTON, Robert; Administração da Produção. 2. ed. São Paulo: ATLAS, 2002.

VAZ, Greice R. M.; Maturidade do processo de desenvolvimento de produto e certificação da qualidade: Coerência Encontrada no Setor de Eletroeletrônico De Manaus. 2010. 128 f. Dissertação (Mestrado em Engenharia) - Programa de Pósgraduação em Engenharia Mecânica e de Materiais, Universidade Tecnológica Federal do Paraná, Curitiba, 2010.

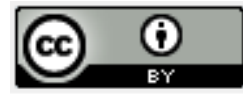

Artigo recebido em 14/11/2012 e aceito para publicação em 05/05/2014 DOI: http://dx.doi.org/10.14488/1676-1901.v14i2.1483

Revista Produção Online, Florianópolis, SC, v.14, n. 2, p. 679-702, abr./jun. 2014. 